\title{
Anterior transhepatic approach for caudate lobectomy
}

\author{
Bin Xu, Weihua Yu, Shuyou Peng, Guanyu Wang \\ Department of General Surgery, Sir Run Run Shaw Hospital, School of Medicine, Zhejiang University, Hangzhou 310016, China \\ Correspondence to: Guanyu Wang. Department of General Surgery, Sir Run Run Shaw Hospital, School of Medicine, Zhejiang University, Hangzhou \\ 310016, China. Email: wangguanyu@zju.edu.cn.
}

\begin{abstract}
A solitary liver tumor was found in a 64-year-old female. Magnetic resonance imaging (MRI) showed the tumor was located in the caudate lobe of the liver (6 cm diameter); almost all caudate lobe was occupied by the tumor. Anterior transhepatic approach was used for isolated complete resection of the caudate lobe through a reversed L-shaped incision, without sacrificing other part of the liver. The postoperative course of the patient was uneventful. The final pathological result showed a cholangiocarcinoma with a part of inferior vena cava (IVC) wall involved.
\end{abstract}

Keywords: Caudate lobe; complete resection; anterior transhepatic approach; liver

Submitted Jul 23, 2018. Accepted for publication Aug 05, 2018.

doi: $10.21037 /$ tcr.2018.08.26

View this article at: http://dx.doi.org/10.21037/tcr.2018.08.26

\section{Introduction}

The caudate lobe is an independent anatomic segment and it consists of the spiegel lobe, the caudate process and paracaval portion $(1,2)$. The caudate lobe lies between major vascular structures, the inferior vena cava (IVC) posteriorly and the portal triads inferiorly and the hepatic venous anteriorly and superiorly. Nowadays, we can perform all kinds of hepatic resection safely. However, even now, hepatic resection of the tumor located in the caudate lobe remains difficult and challenging to the surgeon, even when the tumor is small, due to anatomic complexity. In this video, we shared our experience of the isolated complete caudate lobectomy through anterior transhepatic approach in a 64-year-old female patient with a bulky tumor originating in the caudate lobe (Figure 1).

\section{Operative technique}

A solitary liver tumor was found in a 64-year-old female. The Magnetic resonance imaging (MRI) of the caudate lobe of the liver ( $6 \mathrm{~cm}$ diameter) showed it occupied almost all the caudate lobe, surrounded by the IVC, the porta hepatis, and the main hepatic veins. The physical examination showed no positive signs. Lab tests [HBV-ab(+), total bilirubin $42.5 \mu \mathrm{mol} /$ L] and the rest of test results were normal. We planned to perform a caudate lobectomy through anterior transhepatic approach in this patient. After intubation, the patient lied in the supine position and a laparotomy was performed through a reversed L-shaped incision with right lateral extension to the midaxillary line. After intraoperative ultrasonography and visual inspection confirmed there was no metastatic disease in the liver and peritoneal cavity, both side ligamentous attachments of liver were mobilized and freed. The short hepatic veins between caudate lobe and the IVC were dissected and ligated from a caudal to cranial direction from both sides, until the caudate lobe was well separated and freed from the retrohepatic IVC. After that, hepatoduodenal ligament, infrahepatic IVC and the right hepatic vein (RHV)were taped for temporary hepatic vascular occlusion, in case it was needed. After mobilization of both hepatic lobes completely, hepatic hilum was exposed by removing the gallbladder. The next step was to split the liver through the midplane. Incisional line on liver surface was marked with an electrome from the left side of the root of the middle hepatic vein (MHV) to the fossa of gallbladder. Transection was carried on until the MHV was exposed and identified. Then parenchymal transection was performed along the left side of the MHV until it reached the confluence of the MHV and the left hepatic vein. During the transection, the margin of the tumor should be kept intact and whenever possible, a margin of $0.5 \mathrm{~cm}$. The tumor was closely attached to the major hepatic vein, which could be pushed away from the tumor. When the transection reached the hilar plate, the blood supply and bile ducts to the caudate lobe from the porta hepatis could be identified easily. A series of caudate portal triads were isolated and divided around the hilum. At this point the tumor has been detached from the IVC and hepatic pedicle. During the transection, attention should be drawn to the detachment of hepatic veins. Minute veins between the caudate lobe and hepatic vein should be ligated and divided carefully. Then the caudate lobe can be easily dissected from the right and left lobe of the liver. After removal of the caudate lobe, the retrohepatic IVC, the MHV, the root of the RHV, and the bifurcation of the portal pedicle were exposed completely at the same time. 


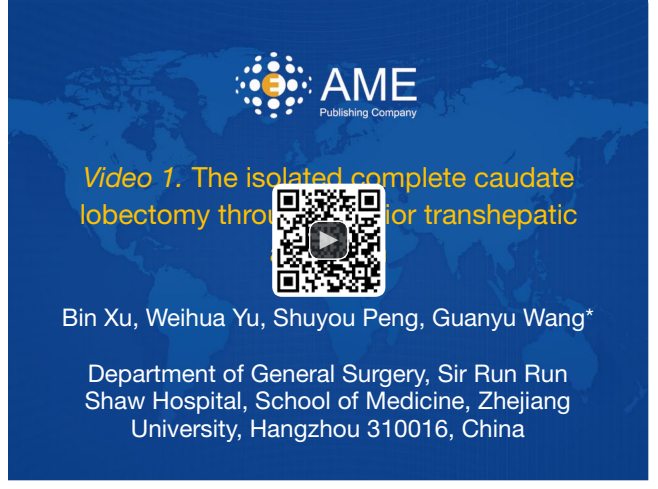

Figure 1 The isolated complete caudate lobectomy through anterior transhepatic approach (3).

Available online: http://www.asvide.com/article/view/26847

\section{Discussion}

The caudate lobe is an independent anatomic segment. Its unique anatomical location, close connection to important structures and being surrounded by major blood vessels makes isolated caudate lobectomy a technical challenge $(1,2)$. The surgical approach to complete caudate lobectomy usually depends on the location and size of the tumor. In the literature (4-6) the most common procedures for complete resection of the caudate lobe include: the left-, right-sided, and the anterior transhepatic approach, or a combination of two-sided approaches. The sided approaches for complete resection of caudate lobe usually need combining with major hepatic lobectomy. If isolated complete caudate lobectomy was performed, the major problems are the dissection and control of the retrohepatic caudate veins and anteriorly, especially dealing with bleeding from tearing the MHV (5). However, the anterior transhepatic approach can provide excellent and directed surgical view, by splitting the liver parenchyma anteriorly through the midplane; it is safe for controlling the bleeding from tearing the MHV. The anterior transhepatic approach provides a good access to perform an isolated complete resection of the caudate lobe. Meanwhile, it can preserve more liver parenchyma. This procedure is suitable for the large tumor or one in close contact with IVC and hepatic veins, or tumor located in paravacal portion, in patient with poor liver function reserve and intolerance of major liver resection.

\section{Acknowledgments}

Funding: None.

\section{Footnote}

Conflicts of Interest: All authors have completed the ICMJE uniform disclosure form (available at http://dx.doi. org/10.21037/tcr.2018.08.26). The authors have no conflicts of interest to declare.

Ethical Statement: The authors are accountable for all aspects of the work in ensuring that questions related to the accuracy or integrity of any part of the work are appropriately investigated and resolved. All procedures performed in study involving human participants were in accordance with the ethical standards of the institutional and/or national research committee(s) and with the Declaration of Helsinki (as revised in 2013). Written informed consent was obtained from the patient for publication of this manuscript.

Open Access Statement: This is an Open Access article distributed in accordance with the Creative Commons AttributionNonCommercial-NoDerivs 4.0 International License (CC BYNC-ND 4.0), which permits the non-commercial replication and distribution of the article with the strict proviso that no changes or edits are made and the original work is properly cited (including links to both the formal publication through the relevant DOI and the license). See: https://creativecommons. org/licenses/by-nc-nd/4.0/.

\section{References}

1. Kumon M. Anatomy of the caudate lobe with special reference of portal vein and bile duct (in Japanese with English abstract). Acta Hepatol Jpn 1985;12:1193-9.

2. Kumon M. Anatomical Study of the Caudate Lobe with Special Reference to Portal Venous and Biliary Branches Using Corrosion Liver Casts and Clinical Application. Liver Cancer 2017;6:161-70.

3. Xu B, Yu W, Peng S, et al. The isolated complete caudate lobectomy through anterior transhepatic approach. Asvide 2018;5:729. Available online: http://www.asvide.com/ article/view/26847

4. Yamamoto J, Takayama T, Kosuge T, et al. An isolated caudate lobectomy by the transhepatic approach for hepatocellular carcinoma in cirrhotic liver. Surgery 1992;111:699-702.

5. Bartlett D, Fong Y, Blumgart LH. Complete resection of the caudate lobe of the liver: technique and results. Br J Surg 1996;83:1076-81.

6. Chaib E, Ribeiro MA Jr, Souza YE, et al. Anterior hepatic transection for caudate lobectomy. Clinics (Sao Paulo) 2009;64:1121-5.

Cite this article as: $\mathrm{Xu} \mathrm{B,} \mathrm{Yu} \mathrm{W,} \mathrm{Peng} \mathrm{S,} \mathrm{Wang} \mathrm{G.} \mathrm{Anterior}$ transhepatic approach for caudate lobectomy. Transl Cancer Res 2018;7(4):1166-1167. doi: 10.21037/tcr.2018.08.26 